\title{
Heat Transfer Enhancement in Separated and Vortex Flow
}

\author{
A Final Project Report \\ Submitted by \\ Dr. Richard J. Goldstein \\ Heat Transfer Laboratory \\ Department of Mechanical Engineering \\ University of Minnesota \\ 111 Church St. SE, Minneapolis, Minnesota \\ Reference: DOE Award No. DE-FG02-94ER14437 \\ Grant Period: $1^{\text {st }}$ September $1998-31^{\text {st }}$ August 2003
}

May 27, 2004 


\section{INTRODUCTION}

This document summarizes the research performance done at the Heat Transfer Laboratory of the University of Minnesota on heat transfer and energy separation in separated and vortex flow supported by DOE in the period $1^{\text {st }}$ September $1998-31^{\text {st }}$ August 2003.

Unsteady and complicated flow structures in separated or vortex flows are the main reason for a poor understanding of heat transfer under such conditions. The research from the University of Minnesota focused on the following important aspects of understanding such flows.

- Heat/mass transfer from a circular cylinder.

- Study of energy separation and heat transfer in free jet flows and shear layers.

- Study of energy separation on the surface and in the wake of a cylinder in crossflow.

The current study used three different experimental setups to accomplish these goals. A wind tunnel and a liquid tunnel using water and mixtures of ethylene glycol and water, is used for the study of Prandtl number effect with uniform heat flux from the circular cylinder. A high velocity air jet is used to study energy separation in free jets. A high speed wind tunnel, same as used for the first part, is utilized for energy separation effects on the surface and in the wake of the circular cylinder.

The final outcome of this study is a substantial advancement in this research area. The details of the results are explained in the following sections.

\section{$\underline{\text { RESULTS }}$}

\section{Heat/Mass Transfer from Circular cylinder}

The effect of free stream turbulence on heat/mass transfer from circular cylinder re was measured [1]. Also, the effect of Prandtl number on local heat transfer from a circular cylinder in crossflow was studied [2-4]. The Prandtl number is varied from 0.7 to 180 using air, water and six mixtures of ethylene glycol and water as working fluids. The 
Reynolds number is adjusted in the range of 2000 and 100000. A uniformly heated circular cylinder is used in the study to obtain the relationship between the local Nusselt number and both Reynolds number and Prandtl number. For Reynolds number higher than 5000, the distribution of local Nusselt number has three distinct regions where, heat transfer is found to increase after the separation due to reattachment and alternate vortex shedding. For Reynolds number less than 5000, the effect of Prandtl number on the heat transfer downstream of the separation point is small. However, Prandtl number still strongly influences heat transfer on the front part of the cylinder.

Experiments of mass transfer from a circular cylinder in fluidized bed were conducted [5]. Heat/mass transfer results around a $90^{\circ}$ bend in square duct were obtained [6]. The heat/mass transfer analogy is experimentally validated under laminar and turbulent boundary layer conditions [7]. Flow visualization of a jet impinging on a circular cylinder was studied to obtain heat transfer characteristics from the cylinder surface $[8,9]$. Detail effects of jet impingement on the heat transfer from convex and concave surfaces are described in references [10-14].

\section{Study of Energy Separation in Free Jet Flows and Shear Layers}

Energy separation is the spontaneous redistribution of energy within the flow, which occurs, in separated flow and vortex flow. The mechanism of energy separation in a free jet flow and shear layer was investigated both numerically and experimentally [1517]. The enhancement of energy separation due to acoustic excitation was also studied. The experimental results show that the frequencies of the dominant total temperature fluctuations coincide with those of velocity fluctuations, which represent the passing frequencies of ring vortices. The study confirms that the mechanism of energy separation is induced by motion of the coherent structure, which generates pressure fluctuations within the flow field [18-19]. These results are supported by flow visualization and numerical results $[20,21]$. 


\section{Study of Energy Separation on the surface and in the wake of Circular cylinder}

The existence of energy separation on the surface of circular cylinder in crossflow and its enhancement due to acoustic excitation was studied in detail [22]. The results indicate that alternate vortex shedding in the wake of cylinder is the cause of energy separation. The vortices are strengthened due to acoustic excitation and hence the magnitude of energy separation. The study is extended to the wake of cylinder and evidence of energy separation was found as far as ten diameters downstream. The vortical structures causing pressure fluctuations are found to be the cause of this effect. The details of the results can be seen in $[23,24]$.

\section{Publications:}

1. Sanitjai, S. and Goldstein, R.J. "Effect of free stream turbulence on local mass transfer from a circular cylinder", International Journal of Heat and Mass Transfer, 44(15): pp. 2863-2875. (Aug. 2001)

2. Sanitjai, S. Effects of the Prandtl Number on Local Heat Transfer from a Circular Cylinder in Crossflow. Ph.D. Thesis, University of Minnesota. (2002)

3. Sanitjai, S. and Goldstein, R. J. "Heat Transfer from a cylinder to mixtures of water and ethylene glycol", submitted to International Journal of Heat and Mass Transfer.

4. Sanitjai, S. and Goldstein, R.J. "Forced Convection heat transfer from a circular cylinder in crossflow to air and liquids", submitted to International Journal of Heat and Mass Transfer.

5. Garim, M. M., Freire, J. T. and Goldstein, R. J. "Local mass transfer coefficients around a cylinder in a fluidized bed" Congresso Brasileiro de Sistemas Particulados (XXV ENEMP) 2,pp. 657-664. (1998)

6. Jabbari, M. Y., Burns, D. V. and Goldstein, R. J. "Mass Transfer downstream of a 90 degree bend in a square duct", Proceedings of the $11^{\text {th }}$ International Heat Transfer Conference 3 pp. 115-120. (1998) 
7. Lee, M. The Analogy between heat and mass transfer on flat surfaces. Master's Thesis. University of Minnesota. (2002)

8. Goldstein, R. J., Cornaro, C. and Fleischer, A. S. "A visualization study of jet impingement on cylindrical surfaces" Applied optical measurements, Springer, Berlin, edited by M. Lehner and D. Mewes pp. 307 - 317. (1999)

9. Cornaro, C., Fleischer, A. S. and Goldstein, R. J. "Flow visualization of a round jet impinging on cylindrical surfaces" Exp Therm Fluids Sci, Elsevier Science, 20, pp. 66-78. (1999)

10. Cornaro, C., Fleischer, A. S. and Goldstein, R. J. "Jet impingement on concave and convex surfaces" Proceedings of $8^{\text {th }}$ International symposium on flow visualization, pp. 236.1- 236.12 (1998)

11. Han, B. and Goldstein, R. J. "Impingement cooling", Aero-Thermal Performance of Internal Cooling Systems in Turbomachines, Lecture series 2000-03, von Karman Institute, Belgium, T. Arts (2000)

12. Fleischer, A. S., Kramer, K. and Goldstein, R. J. "Dynamics of the vortex structure of a jet impinging on a convex surface" Exp Therm Fluid Sci $\mathbf{2 4}$ pp. 169175. (2001)

13. Han, B. and Goldstein, R.J. "Jet impingement heat transfer in gas turbine systems", Heat transfer in gas turbine systems, Annals of the New York academy of sciences, 934: pp.147-161. (2001)

14. Cornaro, C., Fleischer, A. S., Rounds, M. and Goldstein, R. J. "Jet impingement cooling of a convex semi-cylindrical surface" International Journal of Thermal Science, 40 (10): pp. 890-898. (2001)

15. Han, B. and Goldstein, R. J. "Instantaneous Energy Separation in Shear Layer" In Proceedings of the Seventeenth Symposium on Energy Engineering Science, pp. 63-73. Argonne National laboratory, Argonne, Illinois. (1999)

16. Han, B., Goldstein, R. J. and Choi, H. G. "Energy separation in shear layers", International Journal of Heat and Mass Transfer, 45(1): pp. 47-55. (Jan. 2002)

17. Han, B. and Goldstein, R. J. "A numerical study of energy separation in a jet flow" $I^{\text {st }}$ International conference in Heat Transfer, Fluid Mechanics and Thermodynamics 1 pp. 319-324. (2002) 
18. Han, B. and Goldstein, R. J. "Instantaneous energy separation in a free jet Part I: flow measurement and visualization", International Journal of Heat and Mass Transfer, 46(21): pp. 3975-3981. (Oct. 2003)

19. Han, B. and Goldstein, R. J. "Instantaneous energy separation in a free jet Part II: total temperature measurement", International Journal of Heat and Mass Transfer, 46(21): pp. 3975-3981. (Oct. 2003)

20. Seol, W. S. and Goldstein, R. J. "Visualization if the effect of acoustic excitation on vortex structure and energy separation in jets" Proceedings of the $11^{\text {th }}$ International Heat Transfer Conference, 5 pp. 577-582. (1998)

21. Han, B. Instantaneous Energy Separation in a jet flow. Ph.D. Thesis, University of Minnesota. (2001)

22. Goldstein, R. J., and He B. "Energy separation and acoustic interaction in flow across a circular cylinder". Trans. of ASME, Journal of Heat Transfer, 123 pp.682-687. (August 2001)

23. Terala, P. Study of energy separation in the wake of a cylinder for high speed flow. Master's Thesis, University of Minnesota. (2000)

24. Kulkarni, K. Study of Energy Separation in the Wake of a Cylinder. Master's Thesis. University of Minnesota. (2003) 